\title{
AS REPRESENTAÇÕES SOCIAIS DE CIDADE DESENVOLVIDA NOS MUNICÍPIOS PAULISTAS DE JABOTICABAL, OLÍMPIA E BEBEDOURO
}

\author{
Julio Cesar BELLINGIERI ${ }^{1}$
}

\section{Resumo}

Este trabalho identificou as representações sociais de cidade desenvolvida construídas pelos sujeitos de três municípios do interior do Estado de São Paulo: Jaboticabal, Olímpia e Bebedouro. A análise baseou-se na abordagem do Núcleo Central das representações sociais, apoiada na técnica da evocação livre de palavras (ABRIC, 2001), com uso do software EVOC 2000 (VERGÈS, 2002). Foram entrevistadas amostras de 408 pessoas em cada município, estratificadas por sexo, idade, renda e escolaridade. Os resultados mostraram que uma cidade desenvolvida é representada essencialmente por uma dimensão econômica (materializada em emprego e indústrias/empresas), coexistindo com uma dimensão social (materializada em saúde e educação), fazendo emergir o paradigma do desenvolvimento humano (medido pelo IDH). Assim, apesar de o desenvolvimento continuar a ser representado pelo velho paradigma do desenvolvimento econômico (calcado na industrialização), já incorporou atributos de ordem social, não corroborando, assim, outros estudos que apontaram para a representação/percepção/ visão do desenvolvimento como um fenômeno ligado exclusivamente à expansão e/ou ao dinamismo econômico/industrial. Também, o tamanho e/ou a expansão urbana/ demográfica mostrou-se muito pouco relevante, assim como foi nula a dimensão ambiental (base do paradigma do desenvolvimento sustentável), nas representações de cidade desenvolvida.

Palavras-chave: Desenvolvimento. Representações sociais. Cidades. IDHM.

\section{Abstract \\ Social Representations of the developed city in the cities of Jaboticabal, Olímpia e Bebedouro, in the State of São Paulo}

This work has identified the social representations of the developed city created by individuals of three cities in the countryside of the State of São Paulo: Jaboticabal, Olímpia and Bebedouro. The analysis was based on the Central Nucleus approach of the social representations supported by the free evocation of words technique (ABRIC, 2001), using EVOC 2000 software (VERGÈS, 2002). We interviewed samples of 408 people in each city, stratified by sex, age, income and schooling. Results have showed that a developed city is essentially represented by an economic dimension (materialized in employment and industries/companies), which coexists with a social dimension (materialized in health and education), and this engenders the paradigm of human development (measured by HDI). Therefore, although development is still represented by the old paradigm of economic development (based on industrialization), it has already incorporated characteristics of social order, which does not confirm other studies that pointed to the representation/perception/vision of the development as a phenomenon exclusively associated to the economic/social expansion and/or to its dynamism. Also, the city size and/or the urban/demographic expansion have proved to be of little relevance as well as the environmental dimension (basis of the sustainable development paradigm) was null in the representations of the developed city.

Key words: Development. Social representations. Cities. MHDI.

\footnotetext{
${ }^{1}$ Doutor em Geografia pela UNESP/Rio Claro. Docente do Centro Universitário Unifafibe (Bebedouro-SP) e da Faculdade de Educação São Luís (Jaboticabal-SP). Endereço: Rua São Sebastião, 400, ap. 1204, Jaboticabal-SP, CEP: 14870-720.E-mail: julio@asbyte.com.br
}

GeOgRAFIA, Rio Claro, v. 42, n. 2, p. 263-279, mai./ago. 2017. 


\section{INTRODUÇÃO}

Em determinados municípios do interior do Estado de São Paulo, um assunto recorrente em editoriais de jornais, em discursos dos políticos, em conversas cotidianas e nas redes sociais é a (suposta) perda do desenvolvimento de suas localidades. A essência desse pensamento pode ser resumida pelas seguintes afirmações: "Nossa cidade parou no tempo, precisamos voltar a nos desenvolver!"; "Outras cidades estão desenvolvendo-se e nós, não!".

Nestes municípios, o "desenvolvimento perdido" parece relacionar-se à falta de emprego e de indústria, e à estagnação do crescimento demográfico e urbano da cidade. O desenvolvimento parece ser percebido como sinônimo de expansão econômica e urbana, e as cidades que não a vivenciam não estariam desenvolvendo-se.

Esta visão estaria até mesmo incorporada (e, porque não, seria emanada) pelos poderes executivos locais. Para estes, a atração de empresas (especialmente grandes empresas industriais) é sinônimo de desenvolvimento; tese que, segundo Rodríguez-Pose e Arbix (1999), está profundamente enraizada no Brasil.

Souza (2007) afirma que é muito comum confundir desenvolvimento com expansão e crescente complexidade do tecido urbano, na esteira do crescimento econômico e da modernização tecnológica. "Para algumas pessoas, uma cidade 'desenvolve-se' ao crescer, ao se expandir, ao conhecer uma modernização do seu espaço e dos transportes, ao ter algumas áreas embelezadas e remodeladas" (Ibid., p. 95).

Assim, a partir dessas suposições, surgiram as seguintes perguntas de pesquisa deste trabalho: Qual a representação social de cidade desenvolvida construída pelos sujeitos sociais locais? Diferentes grupos sociais, distinguidos em função de sexo, idade, renda e escolaridade, constroem diferentes representações sociais de cidade desenvolvida? Como estas representações se situam perante os diferentes paradigmas do desenvolvimento, tais como desenvolvimento econômico, humano e sustentável?

Parte-se da hipótese de que, nestes municípios, o desenvolvimento é definido pelo tamanho/expansão demográfica/urbana da cidade e pelo crescimento da economia, refletido na quantidade de empregos e de empresas, principalmente indústrias. Ou seja, supõe-se que os sujeitos locais representam o desenvolvimento como expansão populacional/urbana e crescimento econômico/industrial, não tendo incorporado os novos paradigmas ligados a esse conceito, tais como o desenvolvimento sustentável e o humano.

O trabalho tem como objeto de estudo a análise de três municípios do interior do Estado de São Paulo: Jaboticabal, Olímpia e Bebedouro, que reúnem características consideradas importantes para a análise: têm tamanhos demográficos semelhantes $^{2}$, ocupam hierarquia semelhante na rede de cidades brasileiras - tomando-se por referência o REGIC 2007, estudo do IBGE que apontou as regiões de influência das cidades do País (INSTITUTO BRASILEIRO DE GEOGRAFIA E ESTATÍSTICA, 2008) - e, principalmente, têm vivido distintas trajetórias econômicas no período recente, as quais podem (ou não) determinar diferentes representações de cidade desenvolvida por parte de seus habitantes.

\footnotetext{
2 Segundo Sposito (2006, p. 175), embora não haja consenso sobre estes parâmetros, no Brasil, "o que se denomina como 'cidades de porte médio' são aquelas que têm entre 50 mil e 500 mil habitantes", que é o caso dos municípios em análise. Porém, deve-se registrar que cidade de porte médio não é sinônimo de cidade média, uma categoria que vai além da dimensão demográfica e leva também em conta nível de especialização, diversificação econômica, organização espacial e influência regional (AMORIM FILHO; SENA FILHO, 2005).
} 


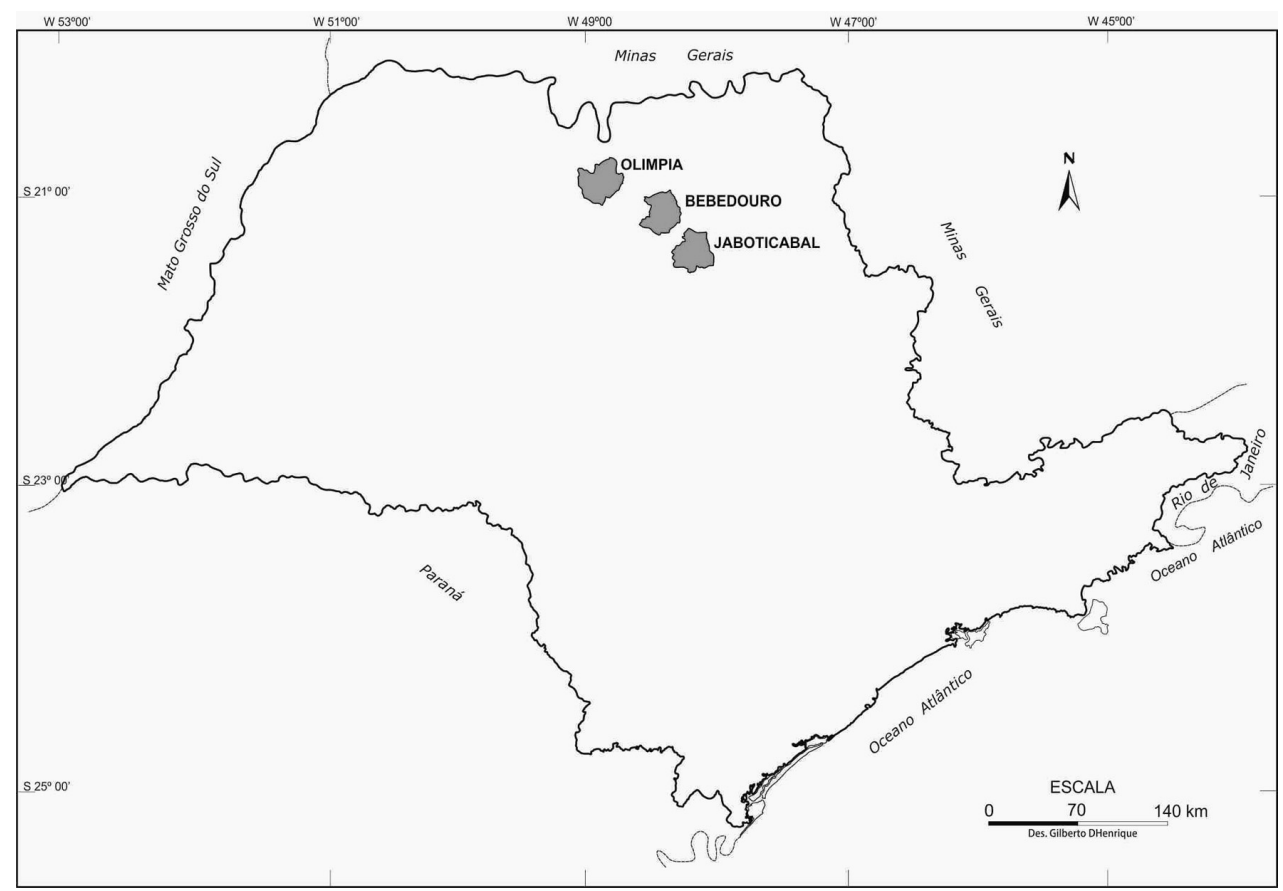

Figura 1 - Localização de Jaboticabal, Olímpia e Bebedouro

Fonte: CIAGRO/CATI - Unesp

Jaboticabal está localizado na Mesorregião de Ribeirão Preto e na Microrregião de Jaboticabal; possui 71.662 habitantes e taxa de urbanização de 97,02\%. Olímpia fica na Mesorregião e na Microrregião de São José do Rio Preto; possui 50.024 habitantes e taxa de urbanização de 94,44\%. E Bebedouro localiza-se na Mesorregião de Ribeirão Preto e na Microrregião de Jaboticabal; tem 75.035 habitantes e taxa de urbanização de 95,29\% (PNUD; IPEA; FJP, 2013).

Jaboticabal tem economia relativamente estável - entre 1999 e 2012, sua participação no PIB estadual mantém-se entre $0,13 \%$ e $0,14 \%$, segundo a Fundação Seade (2015) - , centrada na agroindústria sucroalcooleira, na indústria cerâmica produtora de filtros de água e no ensino, com cinco instituições de ensino superior.

Olímpia possui base agroindustrial, com produção de laranja e de cana-deaçúcar. No entanto, a transformação de um clube de águas quentes num parque aquático de importância turística nacional determinou, a partir de meados da década de 2000, forte boom turístico e imobiliário (com dezenas de hotéis, resorts, etc., em operação e em construção), definindo novo perfil econômico para o município, ratificado em 2014, quando Olímpia recebeu o título oficial de Estância Turística (PREFEITURA MUNICIPAL DE OLÍMPIA, 2015).

Bebedouro, considerada a Capital Nacional da Laranja, por possuir forte produção citrícola e empresas processadoras de suco de laranja, apresentou forte dinamismo econômico durante as décadas de 1970/1980. No entanto, desde o final da década de 1980, transformações no setor citrícola, motivadas pelo baixo preço da laranja, pela queda da demanda mundial por suco de laranja e pelo aumento de custos de 
produção no setor (BELLINGIERI; BORGES; SOUZA, 2012), trazem crises recorrentes à citricultura, repercutindo negativamente na economia bebedourense, com forte volatilidade do PIB e do emprego formal, e queda absoluta dos empregos industriais. Entre 1999 e 2012, a participação de Bebedouro no PIB estadual caiu de 0,49\% para 0,25\% (FUNDAÇÃO SEADE, 2015).

Em 2010, dentre os 5.565 municípios brasileiros, Jaboticabal encontra-se no $145^{\circ}$ lugar no ranking do Índice de Desenvolvimento Humano Municipal (IDHM), Olímpia é o $197^{\circ}$ e Bebedouro o $128^{\circ}$, sendo os três municípios classificados como de alto desenvolvimento humano (PNUD; IPEA; FPJ, 2013) ${ }^{3}$.

Neste artigo, a seção 1 trata como o conceito/paradigma do desenvolvimento variou ao longo do tempo. A seção 2 define a Teoria da Representação Social e faz uma breve revisão dos principais estudos sobre representação de desenvolvimento, ao nível de municípios. A seção 3 descreve o método da pesquisa, e a seção 4 apresenta seus resultados. Nas Considerações Finais, interpretam-se os resultados.

\section{EVOLUÇÃO DO CONCEITO DE DESENVOLVIMENTO}

Segundo Sachs (2008, p. 25), a multidimensionalidade e a complexidade do desenvolvimento explicam seu caráter fugidio e, "como seria de se esperar, o conceito tem evoluído durante os anos, incorporando experiências positivas e negativas, refletindo as mudanças nas configurações políticas e as modas intelectuais".

Com sua origem assentada na noção de progresso - enraizado na civilização com o advento da modernidade, a partir da metade do século XVIII (SZTOMPKA, 2005) - o atual conceito de desenvolvimento nasceu em meados da década de 1940, " [...] como uma idée-force a orientar a reconstrução do pós-guerra e, logo em seguida, o processo de descolonização [...] para tornar-se, lado a lado com a preservação da paz, a pedra de toque da filosofia de ação das Nações Unidas" (SACHS, 2001, p. 163; VEIGA, 2010).

Escobar (2007) considera o discurso de posse do presidente dos EUA, Harry Truman, proferido em 20 de janeiro de 1949, como a inauguração do desenvolvimento enquanto conceito ideológico, quando ele se referiu a áreas subdesenvolvidas. A partir daí, então: a) fundou-se a divisão do mundo entre países desenvolvidos e subdesenvolvidos; b) preconizou-se a "necessidade" de os países subdesenvolvidos almejarem o modelo de desenvolvimento dos países industrializados, para o que deveriam adotar políticas voltadas ao crescimento econômico e à industrialização; c) institucionalizou-se a busca do desenvolvimento, que seria efetivada com o auxílio de organismos internacionais (ONU, Banco Mundial, FMI, etc.). Assim, o desenvolvimento era determinado pela industrialização e era sinônimo de crescimento econômico, medido por um indicador de atividade econômica, o PIB per cápita.

Mas, já a partir da década de 1960, passou a haver uma guinada nos estudos sobre desenvolvimento, de uma abordagem centrada exclusivamente no padrão de vida, associado ao nível de consumo, para uma abordagem que enfatizava os indicadores sociais, levando também em conta o bem-estar da população (VITTE et al., 2002). Assim, nas décadas de 1960 e 1970, já se pode considerar a existência de um

\footnotetext{
3 Deve-se registrar que a divulgação do IDHM em forma de rankings pode induzir a comparações equivocadas entre municípios díspares em tamanho, localização geográfica e posição na hierarquia territorial, conforme alertou Veiga (2010).
} 
conceito de desenvolvimento social (ou socioeconômico), com ênfase na questão da pobreza.

Mas foi a emergência da problemática ambiental, no final dos anos 60 e início dos 70, a responsável pela primeira grande mutação do conceito de desenvolvimento. Sachs (2000) explica que, depois do entusiasmo pelo crescimento econômico das décadas de 40 e 50 e da descoberta das necessidades básicas nos anos 60, a sobrevivência do planeta, a partir dos anos 70, tornou-se o novo frenesi do desenvolvimento.

Em 1973, num contexto de projeções ambientais alarmistas e à sombra da Primeira Conferência das Nações Unidas sobre Meio Ambiente e Desenvolvimento, realizada no ano anterior, em Estocolmo, surgiu o conceito de ecodesenvolvimento. Mas, como o conceito pressupunha a estagnação voluntária do crescimento econômico como forma de atenuar as agressões contra o ambiente, ele não teve boa aceitação, abrindo caminho para o surgimento e a consolidação, a partir de 1987, do paradigma do desenvolvimento sustentável, que recomendava o crescimento econômico como forma de se reduzir a pobreza e, por consequência, os problemas ambientais (SACHS, 2000).

Em fins da década de 1980, o Programa das Nações Unidas para o Desenvolvimento (PNUD), da ONU, dedicava-se à criação de um indicador sintético que representasse, por si só, o desenvolvimento. Em 1990, foi lançado o Primeiro Relatório sobre o Desenvolvimento Humano do PNUD que, inspirado nas contribuições teóricas de Sen (2000), defende que o crescimento da riqueza econômica não é a finalidade última do desenvolvimento, mas um meio para se ampliarem as capacidades dos indivíduos, entre elas um nível de vida decente, acesso à educação e uma vida longa e saudável (UNITED NATIONS DEVELOPMENT PROGRAMME, 1990).

Neste relatório, é lançado o Índice de Desenvolvimento Humano (IDH) - índice calculado a partir de três indicadores, relacionados à renda, saúde e educação - , o qual se tornou uma medida de desenvolvimento bastante aceita, adaptada por muitos países para uso nacional, inaugurando e institucionalizando, assim, o paradigma do desenvolvimento humano.

Já a partir dos anos 2000, inspirados em estudos que revelaram discrepâncias entre a riqueza material e a percepção de bem-estar da população, alguns autores, tais como Veenhoven (2000), têm defendido que indicadores objetivos não seriam suficientes para tratar de questões como qualidade de vida e satisfação de uma população. Estes autores propõem o uso de indicadores subjetivos (obtidos por meio das próprias declarações/percepções dos indivíduos) para se medir bem-estar e, por consequência, desenvolvimento, inaugurando, assim, o paradigma do desenvolvimento subjetivo.

\section{A TEORIA DA REPRESENTAÇÃO SOCIAL E AS REPRESENTAÇÕES DO DESENVOLVIMENTO}

As representações sociais ${ }^{4}$ significam um conjunto de explicações, afirmações, conceitos e conhecimentos, que se originam na vida diária, construídos coletivamente

\footnotetext{
4 Minayo (2002) trata das origens filosóficas das representações sociais; Guareschi (2002) discute as diferenças entre o conceito de representações sociais e seus "parentes": opinião pública, atitude, mito, estereótipo, cognição social, teoria dos esquemas, teoria da atribuição, ideologia e representação coletiva.
} 
e manifestando-se e propagando-se por meio da linguagem (conversações e meios de comunicação); são uma espécie de teoria do senso comum e equivalem, nas sociedades modernas, aos mitos e às crenças das antigas sociedades.

Segundo o criador do conceito, o psicólogo social Moscovici (2003), as finalidades das representações sociais são tornar familiar algo não familiar, possibilitando que objetos, pessoas ou ideias sejam classificados e rotulados (o que chamou de processo de ancoragem), bem como transformar algo abstrato em concreto, transferindo o que está na mente em algo que exista no mundo físico (processo de objetivação). Assim, as representações sociais tornam a comunicação, dentro de um grupo, relativamente não problemática e reduzem o "vago", através de certo grau de consenso entre seus membros.

Ainda segundo Moscovici (2003, p. 41), uma vez criadas, as representações adquirem vida própria, "circulam, se encontram, se atraem e se repelem e dão oportunidade ao nascimento de novas representações, enquanto velhas representações morrem". E, conforme explica Minayo (2002, p. 110), "por serem ao mesmo tempo ilusórias, contraditórias e 'verdadeiras', as representações podem ser consideradas matéria-prima para a análise do social e também para a ação pedagógico-política de transformação".

Uma das abordagens das representações sociais é a do Núcleo Central, de Jean-Claude Abric e Claude Flament, que dá maior importância aos processos cognitivos e à maneira como se organizam as representações. Segundo Abric (2001), os dois componentes de uma representação são: a) o Núcleo Central, a base comum e consensual da representação, constituído por um ou alguns elementos, em quantidade limitada, que assegura o significado, a consistência e a estabilidade/permanência da representação, sendo ele resistente à mudança, uma vez que toda modificação do Núcleo Central significa a mudança completa da representação; b) os Elementos Periféricos, menos limitantes, mais leves e flexíveis do que o Núcleo Central, cujas funções são concretização, regulação, prescrição de comportamentos, proteção do Núcleo Central e individualização da representação coletiva.

Segundo Spink (1995), a forma mais comum de se acessar as representações é por meio das técnicas verbais, dentre as quais se encontra a associação/evocação livre de palavras - descrita por Bardin (1979) como uma das práticas de análise de conteúdo -, cujo caráter mais espontâneo permite alcançar os elementos estruturais das representações mais rapidamente do que em entrevistas abertas. Uma vez que as representações são resultado de um "contínuo burburinho" e um "diálogo permanente" entre indivíduos, é esse diálogo que o pesquisador precisa acessar, por meio de "material espontâneo, seja ele induzido por questões, expresso livremente em entrevistas ou já cristalizado em produções sociais, tais como livros [...] ou matérias de jornais e revistas" (SPINK, 1995, p. 100).

Existem poucos estudos relacionados às representações, percepções e visões sobre o desenvolvimento (e seus vários aspectos) e que têm o município como recorte de análise. Por exemplo, Durham (1986) detectou as visões dos habitantes da periferia de três cidades paulistas - São José dos Campos, Marília e Rio Claro - a respeito do viver na cidade. Embora não tenha tratado da representação do desenvolvimento em si, o estudo mostrou a valorização da grande indústria como elemento dinamizador da cidade e, por que não, de seu desenvolvimento, resumida na ideia de que a cidade é boa para se viver (por seus recursos e pela tranquilidade), mas faltam os empregos industriais existentes nas grandes cidades.

Dundes (2001) estudou a emergência, a partir da década de 1960, de um discurso e de uma ideologia desenvolvimentista produzidos pelo novo poder político de Presidente Prudente, que preconizava a industrialização/atração de indústrias como a forma mais eficaz de promover o desenvolvimento do município. Saquet e Saquet 
(2006), ao estudarem as implicações territoriais da criação de parques industriais em cidades do sudoeste do Paraná, concluíram que a atração de empresas é a forma predominante de industrializar estes municípios que, no discurso das administrações municipais, seria a única maneira de desenvolver suas localidades.

Souza (2006) identificou a percepção dos habitantes de Camaçari-BA, em relação às empresas instaladas no município, mostrando que, ao mesmo tempo em que $72,9 \%$ dos moradores tinham o que reclamar das empresas (pouco relacionamento com o comércio local, poluição do ar e da água, etc.), $89 \%$ deles também não ficariam satisfeitos caso as empresas saíssem do município. Delfino (2008) analisou os discursos e as práticas de planejamento urbano de três gestões municipais de Jaguaruna-SC, no período de 1997/2008, e concluiu que elas foram orientadas para o crescimento e a modernização da cidade com a intenção de transformá-la em uma cidade grande no futuro, respaldadas por uma ideologia que enxerga o desenvolvimento como sinônimo de crescimento econômico e de industrialização.

Iaochite (2008), estudando o polo cerâmico de Santa Gertrudes-SP, entrevistou os moradores com a questão "O que é desenvolver Santa Gertrudes para você?", cujos resultados demonstraram que o desenvolvimento é considerado mais pelo aspecto econômico do que pela qualidade de vida. Calegaro (2010) apreendeu a visão dos sujeitos sociais de Entre-Ijuís-RS, sobre o que consideram desenvolvimento local sustentável, cujos resultados apontaram para uma visão intermediária entre o desenvolvimento como crescimento econômico e o desenvolvimento sustentável, mas ainda persistindo forte viés econômico.

Martinez (2011), analisando a política pública de atração de empresas para Bebedouro-SP, ao perguntar a uma amostra de 349 habitantes "Qual é considerado o principal ponto forte para o desenvolvimento da cidade?", obteve respostas que revelaram uma concepção de desenvolvimento inteiramente voltada para o crescimento econômico.

Pode-se avaliar que todos estes trabalhos apontam, como resultado, uma representação do desenvolvimento como fenômeno ligado à expansão e/ou ao dinamismo econômico/industrial e crescimento urbano dos municípios estudados.

\section{MÉTOdO DA PESQUisA DE LEVANTAMENTO}

Esta é uma pesquisa de caráter analítico-descritivo, de abordagem qualitativa, efetuada por meio de levantamento. Foi utilizado um questionário semiestruturado, fundamentado na abordagem do Núcleo Central das representações e apoiada na técnica da evocação livre de palavras (ABRIC, 2001) -, que solicita ao respondente falar, em ordem de importância, quatro palavras que vêm à sua cabeça quando se fala em cidade desenvolvida.

Decidiu-se por uma quantidade de entrevistas que fosse próxima ao número da amostra necessária caso este fosse um levantamento estatístico com amostragem aleatória simples que levasse em conta o nível de confiança de $95 \%$ e o erro amostral de $5 \%$. Considerando a população dos municípios, as amostras seriam de 383 em Jaboticabal e em Bebedouro, e de 382 em Olímpia (SANTOS, 2014).

Como as entrevistas em Jaboticabal se encerraram primeiro e somaram 408, esta foi também a quantidade de entrevistas nos demais municípios, para que o número de palavras evocadas fosse praticamente igual, tornando possível a comparação das frequências absolutas das palavras evocadas. As entrevistas foram feitas entre os meses de janeiro e abril de 2014. 
A tabela 1 descreve o perfil dos entrevistados, em cada município. As amostras foram estratificadas, respeitando-se a proporção de sexo, faixa de idade (de acordo com dados do Seade de 2013) e faixa de renda (segundo dados do Censo de 2010 do IBGE), em cada município. Denominou-se de Fundamental a faixa de escolaridade contendo os entrevistados analfabetos e com Ensino Fundamental incompleto e completo; Médio, a faixa dos que possuem Ensino Médio incompleto e completo; Superior, a faixa dos que têm Ensino Superior incompleto, completo e Pós-Graduação.

\section{Tabela 1 - Caracterização das amostras entrevistadas (frequência e \%)}

\begin{tabular}{l|cc|cc|cc}
\hline Estratificação & \multicolumn{2}{|c|}{ Jaboticabal } & \multicolumn{2}{c|}{ Olímpia } & \multicolumn{2}{c}{ Bebedouro } \\
\hline Sexo & Freq. & $\%$ & Freq. & $\%$ & Freq. & $\%$ \\
Homens & 200 & 49,0 & 199 & 48,8 & 202 & 49,5 \\
Mulheres & 208 & 51,0 & 209 & 51,2 & 206 & 50,5 \\
Faixa Etária & & & & & & \\
$16-34$ anos & 163 & $40,0 \%$ & 168 & $41,2 \%$ & 165 & $40,4 \%$ \\
$35-54$ anos & 142 & $34,8 \%$ & 134 & $32,8 \%$ & 138 & $33,8 \%$ \\
55 anos ou mais & 103 & $25,2 \%$ & 106 & $26,0 \%$ & 105 & $25,7 \%$ \\
Faixa de Renda & & & & & & \\
Até 2 sal. mínimos & 248 & $60,8 \%$ & 284 & $69,6 \%$ & 287 & $70,3 \%$ \\
Mais de 2 a 5 sal. mínimos & 113 & $27,7 \%$ & 94 & $23,0 \%$ & 89 & $21,8 \%$ \\
Mais de 5 sal. mínimos & 47 & $11,5 \%$ & 30 & $7,4 \%$ & 32 & $7,8 \%$ \\
Escolaridade & & & & & & \\
Fundamental & 136 & $33,3 \%$ & 127 & $31,1 \%$ & 118 & $28,9 \%$ \\
Médio & 153 & $37,5 \%$ & 212 & $52,0 \%$ & 154 & $37,7 \%$ \\
Superior & 119 & $29,2 \%$ & 69 & $16,9 \%$ & 136 & $33,3 \%$ \\
\hline
\end{tabular}

Fonte: Elaboração própria

Cerca de $90 \%$ dos questionários foram respondidos por entrevista oral, aplicada pelo próprio autor em Jaboticabal, e pelo autor e mais uma equipe treinada, em Bebedouro e Olímpia. Os demais questionários foram autoaplicados, ou seja, os próprios respondentes preencheram-nos.

A análise das palavras evocadas foi feita pelo software Ensemble de Programmes Permettant L'Analyse des Evocations, o EVOC 2000 (VERGÈS, 2002), que possui uma série de programas que permitem dois tipos de análise, a lexicográfica e a categorial.

A análise lexicográfica fornece a frequência de cada palavra - quantas vezes é evocada - e sua ordem média de evocação (OME). Por exemplo, se uma determinada palavra é a primeira a ser evocada por todos os sujeitos, ela tem OME de 1,0; se ela é sempre a quarta (última) a ser evocada, tem OME de 4,0. Assim, quanto mais baixa a $\mathrm{OME}$, mais prontamente a palavra é evocada, em média.

O software distribui as evocações em quatro quadrantes. O primeiro (acima e à esquerda) contém as palavras mais frequentes e mais prontamente evocadas, que 
formam o Núcleo Central, elemento mais importante das representações. O segundo quadrante (acima e à direita) contém as palavras mais frequentes, porém mais tardiamente evocadas, que formam os Elementos Intermediários das representações. 0 terceiro (abaixo e à esquerda) contém as palavras menos frequentes, porém mais prontamente evocadas, formando os Elementos de Contraste. O quarto quadrante (abaixo e à direita) contém as palavras menos frequentes e mais tardiamente evocadas, formando os Elementos Periféricos das representações.

Neste artigo, definiu-se que a frequência mínima para uma palavra incluir-se nos quadrantes é de cerca de $2 \%$ do total das evocações. E a frequência intermediária, isto é, a quantidade de evocações a partir da qual uma palavra é considerada de alta frequência, foi definida como o dobro da frequência mínima, ou seja, a partir de aproximadamente $4 \%$ do total de evocações. Por exemplo, considerando as 1.600 palavras evocadas em Jaboticabal, a frequência mínima foi de 30 ( $1,9 \%$ do total) e a intermediária de $60(3,8 \%)$. Assim, compuseram os quadrantes da análise lexicográfica apenas as palavras evocadas 30 ou mais vezes, denominadas de palavras principais. Dentre as palavras principais, as evocadas entre 30 e 59 vezes são as de baixa frequência (aparecem no terceiro e quarto quadrantes), e as evocadas 60 vezes ou mais são as de alta frequência (aparecem no primeiro e segundo quadrantes).

Também, definiu-se como 2,5 a ordem média de evocação (OME) que divide os quadrantes. Assim, palavras com OME menor que 2,5 foram consideradas prontamente evocadas; com OME de 2,5 ou mais, tardiamente evocadas.

Enquanto a análise lexicográfica se concentra nas palavras principais, a análise categorial considera todas as palavras evocadas, agrupadas em categorias. O pesquisador determina quantas e quais categorias existirão e aloca cada palavra a cada uma delas. A partir daí, o software revela a força/relevância de cada categoria.

Os critérios que determinam a força de uma categoria são: a) a quantidade de palavras diferentes e a soma da frequência destas palavras em relação ao total das evocações: alta participação percentual da categoria, concentrada em poucas palavras, indica uma categoria forte; b) frequência das palavras mais frequentes: uma categoria com alta frequência de palavras principais pode ser considerada forte; c) média das ordens médias de evocação (OME) das palavras que compõem a categoria: quanto menor a $O M E$, mais prontamente as palavras da categoria são evocadas (em média) e mais forte a categoria.

\section{REPRESENTAÇÕES SOCIAIS DE CIDAdE DESENVOLVIDA EM JABOTICABAL, OLÍMPIA E BEBEDOURO}

$\mathrm{Na}$ análise lexicográfica das palavras evocadas, em Jaboticabal, foram mencionadas 202 palavras diferentes, em um total de 1.600 evocadas. Em tese, deveriam ter sido evocadas 1.632 palavras (quatro palavras para cada um dos 408 entrevistados), mas 32 entrevistados não evocaram a quarta palavra. Em Olímpia, foram 182 palavras de um total de 1.607 evocações. E, em Bebedouro, 173 palavras, com 1.599 evocações.

As 11 palavras principais, que compõem os quatro quadrantes da representação em Jaboticabal, equivalem a apenas 5,4\% das 202 palavras diferentes evocadas, mas sua frequência de evocações, somada, é de 1.000 , o que corresponde a $62,5 \%$ das 1.600 evocações. Em Olímpia, as palavras principais, distribuídas nos quatro quadrantes, são 12 (6,6\% do total de 182 palavras diferentes), que correspondem a 
1.029 evocações, 64,0\% do total das 1.607 evocações. Em Bebedouro, há 9 palavras principais (5,20\% das 173 palavras diferentes), as quais somam 1.037 evocações, $64,8 \%$ do total de 1.599 .

O Quadro 1 sintetiza a estrutura das representações sociais de cidade desenvolvida, dada pela análise lexicográfica, nos três municípios.

\section{Quadro 1 - Estrutura das representações sociais de cidade desenvolvida, Jaboticabal, Olímpia e Bebedouro}

\begin{tabular}{|c|c|c|c|c|c|}
\hline \multicolumn{3}{|c|}{ Frequência $>=60$; OME $<2,5$} & \multicolumn{3}{|c|}{ Frequência $>=60 ;$ OME $>=2,5$} \\
\hline Palavra & Freq. & OME & Palavra & Freq. & OME \\
\hline \multicolumn{3}{|l|}{ JABOTICABAL } & \multicolumn{3}{|l|}{ JABOTICABAL } \\
\hline Educação & 151 & 2,411 & Lazer & 61 & 3,410 \\
\hline Emprego & 211 & 2,123 & Segurança & 70 & 3,086 \\
\hline Indústrias/empresas & 120 & 1,858 & & & \\
\hline Saúde & 195 & 2,041 & & & \\
\hline \multicolumn{3}{|l|}{ OLÍMPIA } & \multicolumn{3}{|l|}{ OLÍMPIA } \\
\hline Educação & 169 & 2,379 & Lazer & 80 & 3,150 \\
\hline Emprego & 199 & 2,261 & Segurança & 66 & 2,864 \\
\hline Saúde & 247 & 1,960 & & & \\
\hline \multicolumn{3}{|l|}{ BEBEDOURO } & \multicolumn{3}{|l|}{ BEBEDOURO } \\
\hline Educação & 166 & 2,380 & Lazer & 75 & 3,400 \\
\hline Emprego & 278 & 1,993 & Segurança & 61 & 3,000 \\
\hline Indústrias/empresas & 119 & 2,109 & & & \\
\hline Saúde & 231 & 2,299 & & & \\
\hline \multicolumn{3}{|c|}{ Frequência $<60$ e $>=30 ;$ OME $<2,5$} & \multicolumn{3}{|c|}{ Frequência $<60$ e $>=30 ;$ OME $>=2,5$} \\
\hline Palavra & Freq. & OME & Palavra & Freq. & OME \\
\hline JABOTICABAL & & & JABOTICABAL & & \\
\hline Comércio & 35 & 2,371 & Moradias & 33 & 3,273 \\
\hline \multirow[t]{2}{*}{ Escolas } & 42 & 2,452 & Saneamento & 30 & 2,833 \\
\hline & & & Transporte/público & 52 & 2,615 \\
\hline OLÍMPIA & & & OLÍMPIA & & \\
\hline \multirow[t]{6}{*}{ Indústrias/empresas } & 55 & 2,236 & Administração/boa & 31 & 2,839 \\
\hline & & & Escolas & 38 & 2,737 \\
\hline & & & Faculdades & 30 & 2,600 \\
\hline & & & Limpeza & 34 & 2,706 \\
\hline & & & Moradias & 32 & 2,813 \\
\hline & & & $\begin{array}{l}\text { Transporte/público } \\
\text { BEBEDOURO }\end{array}$ & 48 & 2,708 \\
\hline \multirow{2}{*}{ Hospitais } & 30 & 2,233 & Limpeza & 36 & 2,639 \\
\hline & & & Transporte/público & 41 & 2,683 \\
\hline
\end{tabular}

O Núcleo Central revela que os sujeitos dos três municípios constroem essencialmente a mesma representação social de cidade desenvolvida, representando-a como um fenômeno relacionado ao econômico (materializado no emprego e na existência de indústrias e de empresas) e ao social (materializado na saúde e na educação). A única diferença entre os três municípios é a ausência de indústrias/empresas no Núcleo Central em Olímpia.

Os Elementos Intermediários - a periferia mais próxima do Núcleo Central também são idênticos nos três municípios: lazer e segurança. Segurança pode ser considerado um atributo de dimensão social; já o lazer, um atributo ligado a objetos técnicos/equipamentos urbanos/recursos/infraestrutura (de acordo com o agrupamento das palavras em categorias, descrito mais à frente).

Já os Elementos de Contraste - que podem reforçar os Elementos Intermediários - são diferentes nas três cidades. São compostos por comércio e escolas em 
Jaboticabal, indústrias/empresas em Olímpia e hospitais em Bebedouro. Nos três municípios, as palavras deste quadrante acabam por reforçar não os Elementos Intermediários, mas, sim, os próprios Núcleos Centrais. Em Bebedouro, hospitais, embora sejam aqui considerados objetos técnicos/equipamentos urbanos, estão vinculados à saúde; em Olímpia, indústrias/empresas está relacionada ao emprego (faltaram apenas 5 evocações para indústrias/empresas compor o Núcleo Central); e, em Jaboticabal, escolas vincula-se à educação. Apenas a palavra comércio, de Jaboticabal, não remete ao Núcleo da representação desta cidade, pois é aqui entendida como expressão do tamanho/dimensão urbana da cidade.

Os Elementos Periféricos - elementos mais distantes do Núcleo Central - são mais heterogêneos nos três municípios, embora com algumas coincidências. Transporte/público é o único elemento presente nos três municípios, que remete a objetos técnicos/equipamentos urbanos/recursos/infraestrutura; limpeza e moradias estão presentes em duas cidades, sendo limpeza vinculada à mesma dimensão do transporte, bem como moradias relacionada a uma dimensão social. Saneamento, considerada também um elemento ligado à infraestrutura da cidade, encontra-se exclusivamente em Jaboticabal. E, administração/boa, escolas e faculdades, exclusivamente em Olímpia. Escolas e faculdades, embora sejam considerados objetos técnicos, estão vinculadas à educação (dimensão social), e administração/boa é um atributo político/administrativo.

Diferentes grupos sociais, distinguidos por critérios de sexo, idade, renda e escolaridade, possuem diferentes representações de cidade desenvolvida? Para responder a essa questão, foi feita uma análise lexicográfica para cada uma destas estratificações, em cada município, cujos resultados são descritos a seguir (os quadros das representações, para cada estratificação e município, não são apresentados, em função do limite de espaço).

Não há alterações na essência das representações em função do sexo. Os Núcleos Centrais são idênticos para homens e mulheres, nos três municípios, com a única exceção de que indústrias/empresas não compõe o Núcleo das mulheres em Olímpia. Uma diferença entre os sexos está na comparação entre os Elementos Intermediários e Periféricos, que mostram uma valorização maior da segurança como atributo de cidade desenvolvida para os homens, e do lazer para as mulheres.

As representações de cidade desenvolvida também não se alteram em função da idade dos sujeitos, nos três municípios. Nas três faixas etárias consideradas, o desenvolvimento é evocado dentro de uma dimensão social e econômica: em geral, saúde, educação, emprego e indústrias/empresas estão no Núcleo Central, e educação, lazer e segurança estão nos Elementos Intermediários.

Já a renda é capaz de determinar mudanças nas representações. Em Jaboticabal e Olímpia, na faixa acima de 5 salários, o desenvolvimento, sob a ótica do Núcleo Central, é um fenômeno exclusivamente social (representado por educação e saúde), e não mais socioeconômico - lembrando que, para Abric (2001), modificações do Núcleo Central significam a mudança da própria representação. Em Olímpia, para a faixa acima de 5 salários, indústrias/empresas não figura em nenhum dos quatro quadrantes. Somente em Bebedouro o emprego figura no Núcleo Central das três faixas de renda, mas indústrias/empresas não se encontra no Núcleo da faixa acima de 5 salários, pela única vez em todas as estratificações feitas para o município.

Na estratificação por escolaridade, embora saúde e emprego (ou seja, uma mescla de atributos social e econômico) estejam no Núcleo Central de todas as faixas dos três municípios, observa-se uma diferença importante em duas delas. Em Jaboticabal e em Bebedouro, a educação não faz parte do Núcleo Central nas faixas Fundamental e Médio, passando a fazê-lo somente na Superior. Porém, em Olímpia, ocorre o inverso: educação só não faz parte do Núcleo da faixa Superior. 
Levando agora em conta a análise categorial, a observação das evocações, nos três municípios, levou à construção de sete categorias. A Categoria 1 (Dimensão econômica) representa o paradigma do desenvolvimento econômico. Foram agrupadas as palavras que simbolizam atividades, setores ou indicadores econômicos e que remetem à produção/riqueza material, como, por exemplo, emprego, indústrias/empresas, produção, riqueza, usinas, crescimento/PIB. A Categoria 2 (Dimensão social) representa o paradigma do desenvolvimento social, agregando atributos de caráter social e de qualidade de vida: saúde, educação, segurança, moradias, sem-pobreza, etc.

A Categoria 3 (Objetos técnicos/Equipamentos urbanos/Recursos/Infraestrutura) reúne as palavras que representam como cidade desenvolvida os objetos técnicos, equipamentos urbanos, recursos e infraestrutura, de caráter público, presentes na cidade: lazer, transporte/público, creches, asfalto, hospitais, escolas, praças, etc. Em princípio, algumas destas palavras poderiam estar também relacionadas à Categoria 2 (por exemplo, hospitais ou escolas, que remetem a uma dimensão social). Mas a diferença está no fato de que, enquanto a Categoria 2 evoca um sentido abstrato, genérico, de melhoria social (por exemplo, educação, enquanto processo de aperfeiçoamento das faculdades humanas), a Categoria 3 evoca os equipamentos, as construções, os prédios, num sentido físico (por exemplo, escolas).

A Categoria 4 (Crescimento/Tamanho urbano) agrega as palavras que remetem à expansão urbana e/ou demográfica (crescimento, número-de-habitantes, etc.), bem como a objetos técnicos, de caráter privado, que respondem à espacialidade de grandes centros, considerando a demanda de capital necessário à sua implantação, que raramente tem origem local (comércio, shoppings). A Categoria 5 (Político-administrativo-legal) agrupa as palavras que vinculam o desenvolvimento com a gestão política e administrativa local: administração/boa, prefeito/bom, sem-corrupção, leismelhores. A Categoria 6 (Dimensão ambiental) agrega as palavras que representam uma cidade desenvolvida pelo paradigma do desenvolvimento sustentável: sustentabilidade, meio ambiente, natureza, etc. Por fim, a Categoria 7 (Atributos subjetivos) agrega as palavras abstratas e as passíveis de dúvida quanto a integrarem uma ou outra categoria. Por exemplo, organização, tecnologia, desenvolvimento, movimento, união, povo-bom, calma, etc.

As tabelas 2, 3 e 4 mostram as categorias das representações de cidade desenvolvida, nos três municípios, obtidas por meio do software EVOC 2000.

\section{Tabela 2 - Categorias das representações sociais de cidade desenvolvida, Jaboticabal}

\begin{tabular}{l|c|c|c|c|c|c|c|c|c}
\hline \multicolumn{2}{l|}{ Palavras/Categorias } & Cat. 1 & Cat. 2 & Cat. 3 & Cat. 4 & Cat. 5 & Cat. 6 & Cat. 7 & Total \\
\hline \multirow{2}{*}{ Palavras diferentes } & Quant. & 15 & 40 & 54 & 21 & 12 & 5 & 55 & 202 \\
\cline { 2 - 11 } & $\%$ & 7,4 & 19,8 & 26,7 & 10,4 & 5,9 & 2,5 & 27,2 & 100,0 \\
\hline $\begin{array}{l}\text { Frequência das } \\
\text { palavras }\end{array}$ & Freq. & 364 & 557 & 392 & 99 & 36 & 13 & 139 & 1.600 \\
\cline { 2 - 11 } & $\%$ & 22,8 & 34,8 & 24,5 & 6,2 & 2,3 & 0,8 & 8,7 & 100,0 \\
\hline $\begin{array}{l}\text { Frequência das } \\
\text { palavras mais } \\
\text { frequentes (>=30) }\end{array}$ & $\%$ & 90,9 & 80,6 & 47,2 & 35,4 & 0,0 & 0,0 & 0,0 & 62,5 \\
\hline $\begin{array}{l}\text { OME das palavras da } \\
\text { Categoria }\end{array}$ & & 2,1 & 2,5 & 2,7 & 2,4 & 2,6 & 3,0 & 2,8 & - \\
\hline
\end{tabular}


Tabela 3 - Categorias das representações sociais de cidade desenvolvida, Olímpia

\begin{tabular}{|c|c|c|c|c|c|c|c|c|c|}
\hline \multicolumn{2}{|l|}{ Palavras/Categorias } & Cat. 1 & Cat. 2 & Cat. 3 & Cat. 4 & Cat. 5 & Cat. 6 & Cat. 7 & Total \\
\hline \multirow{2}{*}{ Palavras diferentes } & Quant. & 11 & 25 & 48 & 21 & 8 & 5 & 64 & 182 \\
\hline & $\%$ & 6,0 & 13,7 & 26,4 & 11,5 & 4,4 & 2,7 & 35,2 & 100,0 \\
\hline \multirow{2}{*}{ Frequência das palavras } & Freq. & 297 & 621 & 418 & 85 & 57 & 7 & 122 & 1.607 \\
\hline & $\%$ & 18,5 & 38,6 & 26,0 & 5,3 & 3,5 & 0,4 & 7,6 & 100,0 \\
\hline $\begin{array}{l}\text { Frequência das palavras } \\
\text { mais frequentes }(>=30)\end{array}$ & $\%$ & 85,5 & 82,8 & 55,0 & 0,0 & 54,4 & 0,0 & 0,0 & 64,0 \\
\hline $\begin{array}{l}\text { OME das palavras da } \\
\text { Categoria }\end{array}$ & & 2,3 & 2,3 & 2,7 & 2,4 & 2,6 & 3,3 & 2,8 & - \\
\hline
\end{tabular}

Tabela 4 - Categorias das representações sociais de cidade desenvolvida, Bebedouro

\begin{tabular}{|c|c|c|c|c|c|c|c|c|c|}
\hline \multicolumn{2}{|l|}{ Palavras/Categorias } & \multirow{2}{*}{$\begin{array}{c}\text { Cat. 1 } \\
15 \\
\end{array}$} & \multirow{2}{*}{$\begin{array}{c}\text { Cat. 2 } \\
32 \\
\end{array}$} & \multirow{2}{*}{$\begin{array}{c}\text { Cat. } 3 \\
42 \\
\end{array}$} & \multirow{2}{*}{$\begin{array}{c}\text { Cat. } 4 \\
12 \\
\end{array}$} & \multirow{2}{*}{\begin{tabular}{c|} 
Cat. 5 \\
11 \\
\end{tabular}} & \multirow{2}{*}{\begin{tabular}{c|} 
Cat. 6 \\
2 \\
\end{tabular}} & \multirow{2}{*}{\begin{tabular}{|c|} 
Cat. 7 \\
59 \\
\end{tabular}} & \multirow{2}{*}{\begin{tabular}{|c|} 
Total \\
173 \\
\end{tabular}} \\
\hline Palavras diferentes & Quant. & & & & & & & & \\
\hline & $\%$ & 8,7 & 18,5 & 24,3 & 6,9 & 6,4 & 1,2 & 34,1 & 100,0 \\
\hline \multirow{2}{*}{ Frequência das palavras } & Freq. & 425 & 579 & 352 & 52 & 52 & 8 & 131 & 1.599 \\
\hline & $\%$ & 26,6 & 36,2 & 22,0 & 3,3 & 3,3 & 0,5 & 8,2 & 100,0 \\
\hline $\begin{array}{l}\text { Frequência das palavras } \\
\text { mais frequentes }(>=30)\end{array}$ & $\%$ & 93,4 & 79,1 & 51,7 & 0,0 & 0,0 & 0,0 & 0,0 & 64,9 \\
\hline $\begin{array}{l}\text { OME das palavras da } \\
\text { Categoria }\end{array}$ & & 2,1 & 2,5 & 2,8 & 2,4 & 2,7 & 3,4 & 2,7 & - \\
\hline
\end{tabular}

Levando-se em conta os critérios que determinam a força/relevância de uma categoria, as Categorias 1 e 2 são as mais fortes na representação de cidade desenvolvida, nos três municípios: são compostas predominantemente por palavras principais, têm baixas OME e têm alta participação percentual no total das evocações (a Categoria 2 é a mais frequente nos três municípios, e a 1, a segunda mais frequente em Bebedouro e a terceira em Jaboticabal e em Olímpia); e a Categoria 1 está concentrada em poucas palavras, nos três municípios. A Categoria 3 também é forte nos três municípios, pois, embora não tenha alta participação de palavras principais nem baixa OME, é a segunda mais frequente nas evocações em Jaboticabal e em Olímpia, e a terceira em Bebedouro.

Dessa forma, a análise categorial das evocações mostra uma cidade desenvolvida representada predominantemente por atributos sociais e econômicos, e por objetos técnicos. Já crescimento e/ou tamanho da cidade, aspectos político/administrativos, dimensão ambiental e atributos subjetivos (Categorias 4, 5, 6 e 7, respectivamente) são praticamente irrelevantes na representação do desenvolvimento, nestes municípios.

Assim, a análise categorial ratifica a análise lexicográfica: as palavras que predominam nos Núcleos Centrais (saúde, educação, emprego, indústrias/empresas) correspondem às mais frequentes das Categorias 1 e 2 ; e as que predominam nos 
Elementos Intermediários são frequentes nas Categorias 2 (segurança) e 3 (lazer). Em outras palavras, pode-se dizer que, tanto nos dois principais quadrantes da análise lexicográfica (Núcleo Central e Elementos Intermediários), quanto nas categorias fortes da análise categorial, há a primazia de atributos de ordem social e econômica e, secundariamente, de objetos técnicos.

\section{CONSIDERAÇÕES FINAIS}

Por meio de uma pesquisa de levantamento, este trabalho identificou as representações sociais de cidade desenvolvida, construídas pelos sujeitos de três municípios do interior do Estado de São Paulo: Jaboticabal, Olímpia e Bebedouro. Foi utilizada a abordagem do Núcleo Central das representações sociais, apoiada na técnica da evocação livre de palavras (ABRIC, 2001), com o uso do software EVOC 2000 (VERGĖS, 2002).

Concluiu-se que, nos três municípios, uma cidade desenvolvida é representada essencialmente como um fenômeno econômico e social. O Núcleo Central da análise lexicográfica (dado pelas palavras mais frequentes e mais prontamente evocadas) revelou uma dimensão econômica (materializada nas palavras emprego e indústrias/ empresas) e uma social (materializada em saúde e em educação), da mesma forma que Dimensão econômica e Dimensão social se mostraram as duas categorias mais fortes, dentre as sete identificadas, da análise categorial. Pode-se afirmar que, desta mescla de representações, emerge-se o paradigma do desenvolvimento humano, materializado no IDH e em suas dimensões: Renda, Educação e Longevidade (relacionada à saúde).

A desagregação da análise lexicográfica por grupos sociais mostrou que, nos três municípios, não há diferenças na essência das representações em função de sexo e idade, mas há em função de renda (a dimensão econômica torna-se menos relevante na representação dos de renda mais alta) e de escolaridade (em Jaboticabal e em Bebedouro, a educação não faz parte do Núcleo Central nas faixas Fundamental e Médio, passando a fazê-lo na Superior).

Dentre as palavras que compõem o Núcleo Central das representações, emprego é a mais frequente em Jaboticabal e em Bebedouro, e saúde é a mais frequente em Olímpia. Já as palavras do Núcleo Central mais prontamente evocadas são indústrias/empresas em Jaboticabal, saúde em Olímpia e emprego em Bebedouro. Isso mostra que, apesar de o Núcleo Central revelar uma mescla de atributos econômicos e sociais, o econômico tem um peso mais significativo em dois municípios.

Isto poderia corroborar alguns dos estudos recentes que trataram de representações, percepções e visões sobre o desenvolvimento em diversas cidades, cujos resultados apontaram para sua representação/percepção/visão como um fenômeno ligado à expansão e/ou ao dinamismo econômico/industrial. Mas a diferença crucial em relação a estes estudos é que, aqui, detectou-se que a essência do desenvolvimento não é representada somente pela dimensão econômica, mas também pela social.

A hipótese do tamanho urbano/demográfico como representação de cidade desenvolvida não foi confirmada, uma vez que atributos que evocam o crescimento urbano e/ou populacional praticamente não fazem parte das palavras principais da análise lexicográfica, da mesma forma que Crescimento/Tamanho urbano é uma categoria fraca na análise categorial. 
Também, o paradigma do desenvolvimento sustentável é nulo para definir uma cidade desenvolvida, do ponto de vista da representação dos sujeitos. Nos três municípios, não há uma só palavra que remeta a este paradigma compondo as palavras principais da análise lexicográfica, da mesma forma que a Categoria Dimensão ambiental é a menos relevante de todas, em cada município. Uma cidade desenvolvida, associada com a sustentabilidade, é algo que se encontra fora das mentes dos sujeitos locais.

O fato de ocorrerem representações sociais praticamente idênticas nos três municípios torna os resultados bastante robustos, já que eles vivenciam diferentes momentos econômicos, fazendo com que suas populações manifestem diferentes sentimentos/ânimos, e que, por isso, poderiam construir representações diferentes.

Para outros estudos relacionados a esta temática, sugere-se: a) identificar como o porte/classificação do município ou sua posição na rede urbana determina/ influencia a representação do desenvolvimento; por exemplo, habitantes de municípios pequenos, médios e grandes constroem diferentes representações de cidade desenvolvida?; b) investigar se (como e por que) as representações sociais se alteram ao longo do tempo, num mesmo município ou num conjunto de municípios.

Captar as representações do desenvolvimento significa compreender o que as sociedades pensam e almejam em relação ao seu desenvolvimento, sua identidade comunitária e seu futuro, e pode ser importante para a formulação e a avaliação/ validação de políticas públicas relacionadas à melhoria das condições de vida da população. Conforme já disse Minayo (2002), as representações são matéria-prima para a análise do social e também para a ação pedagógico-política de transformação.

\section{REFERÊNCIAS}

ABRIC, J.-C. O estudo experimental das representações sociais. In: JODELET, Denise (Org.). As representações sociais. Rio de Janeiro: EdUERJ, 2001.

AMORIM FILHO, O. B.; SENA FILHO, N. de. A morfologia das cidades médias. Goiânia: Ed. Vieira, 2005.

BARDIN, Laurence. Análise de conteúdo. Lisboa: Edições 70, 1979.

BELLINGIERI, J. C.; BORGES, A. Cl. G.; SOUZA, J. G. de. Interpretações sobre fatores de exclusão de pequenos agricultores no setor citrícola. Estudos Geográficos, v. 10, p. 27-42, jan./jun. 2012.

CALEGARO, C. F. Uma percepção local do desenvolvimento sustentável: o caso do município de Entre-Ijuís-RS. 2010. Dissertação (Mestrado em Desenvolvimento)" Universidade Regional do Noroeste do Estado do Rio Grande do Sul-Ijuí-RS, 2010.

DELFINO, D. dos S. Desenvolvimento e planejamento urbano na cidade de Jaguaruna-SC: representação e atuação dos atores locais. 2008. Dissertação (Mestrado em Geografia)-Universidade Federal de Santa Catarina, Florianópolis-SC, 2008.

DUNDES, A. C. O poder local e a indústria: uma análise do discurso desenvolvimentista prudentino. In: SPOSITO, M. E. B. (Org.). Textos e contextos para a leitura geográfica de uma cidade média. Presidente Prudente: [s.n.], 2001. 
DURHAM, E. R. A sociedade vista da periferia. Revista Brasileira de Ciências Sociais, n. 1, p. 84-99, 1986.

ESCOBAR, A. La invención del tercer mundo: construcción y deconstrucción del desarrollo. Caracas: Fundación Editorial el perro y la rana, 2007.

FUNDAÇÃO SEADE. Informações dos Municípios Paulistas. 2015. Disponível em: <www.seade.gov.br>. Acesso em: 10 jan. 2015.

GUARESCHI, P. A. "Sem dinheiro não há salvação": ancorando o bem e o mal entre os neopentecostais. In: GUARESCHI, P. A.; JOVCHELOVITCH, S. (Org.). Textos em representações sociais. 7. ed. Petrópolis: Vozes, 2002.

IAOCHITE, J. C. Novos tempos e antigas espacialidades: o polo cerâmico e as inércias espaciais no contexto da produção do espaço urbano de Santa Gertrudes-SP. 2008. Tese (Doutorado em Geografia)-Instituto de Geociências e Ciências Exatas, Universidade Estadual Paulista, Rio Claro, 2008.

INSTITUTO BRASILEIRO DE GEOGRAFIA E ESTATÍSTICA. Regiões de influência das cidades-2007. Rio de Janeiro, 2008. Disponível em: <http://www.ibge.gov.br/ home/ geociencias/geografia/regic.shtm?c=6>. Acesso em: 04 jan. 2015.

MARTINEZ, R. de S. Desenvolvimento local de Bebedouro-SP: análise da política municipal de atração de empresas. 2011. Dissertação (Mestrado em Desenvolvimento Regional)-Centro Universitário de Franca, Franca, 2011.

MINAYO, M. C. de S. O conceito de representações sociais dentro da sociologia clássica. In: GUARESCHI, P. A.; JOVCHELOVITCH, S. (Org.). Textos em representações sociais. 7. ed. Petrópolis: Vozes, 2002.

MOSCOVICI, S. Representações sociais: investigações em psicologia social. Petrópolis: Vozes, 2003.

PNUD; IPEA; FJP. Atlas do Desenvolvimento Humano no Brasil. 2013. Brasília: PNUD Brasil. Disponível em: <www.atlasbrasil.org.br>. Acesso em: 10 jan. 2015.

PREFEITURA MUNICIPAL DE OLÍMPIA. Disponível em: <www.olimpia.sp. gov.br>. Acesso em: 11 jul. 2015.

RODRÍGUEZ-POSE, A.; ARBIX, G. Estratégias do desperdício: a guerra fiscal e as incertezas do desenvolvimento. Revista Novos Estudos, São Paulo, n. 54, p. 55-71, jul. 1999.

SACHS, I. Desenvolvimento: includente, sustentável, sustentado. Rio de Janeiro: Garamond, 2008.

SACHS, I. Repensando o crescimento econômico e o progresso social: o âmbito da política. In: ARBIX, G.; ZILBOVICIUS, M.; ABRAMOVAY, R. (Org.). Razões e ficções do desenvolvimento. São Paulo: Editora Unesp; Edusp, 2001.

SACHS, W. Meio Ambiente. In: SACHS, W. (Org.). Dicionário do desenvolvimento: guia para o conhecimento como poder. Petrópolis: Vozes, 2000.

SANTOS, G. E. de O. Cálculo amostral: calculadora on-line. Disponível em: <http:/ /www.calculoamostral.vai.la>. Acesso em: 12 jan. 2014.

SAQUET, D. B.; SAQUET, M. A. Parques industriais, fluxos e redefinições do espaço urbano. In: SPOSITO, E.; SPOSITO, M. E. B.; SOBARZO, O. (Org.). Cidades médias: produção do espaço urbano e regional. São Paulo: Expressão Popular, 2006.

SEN, A. Desenvolvimento como liberdade. São Paulo: Companhia das Letras, 2000 . 
SOUZA, J. G. de. Camaçari, as duas faces da moeda: crescimento econômico $x$ desenvolvimento social. 2006. Dissertação (Mestrado em Desenvolvimento Regional e Urbano)-Universidade Salvador, Salvador-BA, 2006.

SOUZA. M. J. L. de. ABC do desenvolvimento urbano. 3. ed. Rio de Janeiro: Bertrand Brasil, 2007.

SPINK, M. J. O estudo empírico das representações sociais. In: SPINK, M. J. (Org.). 0 conhecimento no cotidiano: as representações sociais na perspectiva da psicologia social. São Paulo: Brasiliense, 1995.

SPOSITO, M. E. B. Loteamentos fechados em cidades médias paulistas - Brasil. In: SPOSITO, E.; SPOSITO, M. E. B.; SOBARZO, O. (Org.). Cidades médias: produção do espaço urbano e regional. São Paulo: Expressão Popular, 2006.

SZTOMPKA, P. A sociologia da mudança social. 2. ed. Rio de Janeiro: Civilização Brasileira, 2005.

UNITED NATIONS DEVELOPMENT PROGRAMME. Human Development Report 1990. Oxford: Oxford University Press, 1990. Disponível em: <http://hdr.undp.org/en/reports/ global/hdr1990/chapters/>. Acesso em: 15 mar. 2015.

VEENHOVEN, R. The four qualities of life. Journal of happiness Studies, v. 1, p. 1$39,2000$.

VEIGA, J. E. da. Desenvolvimento sustentável: o desafio do século XXI. Rio de Janeiro: Garamond, 2010.

VERGÈS, P. Ensemble de Programmes Permettant L'Analyse des Evocations. EVOC 2000. Manuel. Version 5. 2002. Disponível em: <http://www.pucsp.br/pos/ped/ rsee/ evoc.htm>. Acesso em: 26 abr. 2015.

VITTE, C. de C. S. et al. Novas abordagens de desenvolvimento e sua inserção na gestão de cidades. In: KEINERT, T. M. M.; KARRUZ, A. P. (Org.). Qualidade de vida: observatórios, experiências e metodologias. São Paulo: Annablume; Fapesp, 2002. 